\title{
Reseñasy discusiones
}

Reviews and Discussions 
Serrano Ruiz-Calderón, J. Miguel. 2015. Democracia y nihilismo. Vida y obra de Nicolás Gómez Dávila. Pamplona: Eunsa

Bogdan Piotrowski ${ }^{\diamond}$ Universidad de La Sabana (Colombia)

Para citar este artículo/To reference this article Piotrowski, Bogdan. 2015. "Serrano Ruiz-Calderón, J. Miguel. 2015. Democracia y nihilismo. Vida y obra de Nicolás Gómez Dávila. Pamplona: Eunsa". Pensamiento y Cultura 18 (2): 184-188. DOI: 10.5294/pecu.2015.18.2.9 


\section{Texto explícito sobre los textos implícitos}

No es fácil develar las influencias de los autores en un autor, sobre todo cuando este último es reconocido como un lector culto y voraz. No obstante, José Miguel Serrano Ruiz-Calderón, profesor de Filosofía del Derecho en la Universidad Complutense de Madrid y director académico en el IEB, asumió este reto y bien que lo logró. Si bien es cierto que sus publicaciones indican que se dedica con reconocido éxito a los temas de bioética $y$, fundamentalmente, sobre el aborto y la eutanasia, sus amplios horizontes permiten que nos entregue ahora un nuevo libro, muy diferente, que muestra el pensamiento de Nicolás Gómez Dávila, un filósofo bogotano quien ganó póstumamente fama internacional.

Es importante expresar en estas líneas que el autor comparte el rastreo de una completa bibliografía muy bien elaborada sobre la obra del solitario bogotano, así como la de consulta y de apoyo que usó para su análisis y su argumentación, no solamente en español, sino también en alemán, francés, inglés, italiano y polaco. ¡La lista incluye 178 títulos! El libro ofrece una clara estructura argumentativa, enunciada por los títulos de los capítulos y subcapítulos; por tanto, facilita al lector la comprensión de la obra, de cierto modo, laberíntica, del gran solitario. Indudablemente, no es fácil adentrarse en el mundo gomezdaviliano, laberíntico, lleno de paradojas y marañas; por esta razón, es aún más plausible el esfuerzo.

Después del Prólogo de Julia Escobar y la Introducción, el libro contiene seis capítulos bien nutridos. La prologuista destaca la importancia del homenajeado Gómez Dávila, con motivo del centenario de su nacimiento, y señala las características de la obra de este escritor culto y, a la vez, secreto. La Introducción esboza algunos elementos de la obra de don Colacho y los avatares en su recepción.

El capítulo I "Una Vida sustrato de una obra” es un enlace permanente de la biografía de don Nicolás con su obra. Serrano Ruiz-Calderón destaca el pesimismo de su visión, pero, al mismo tiempo, despliega el inusitado sentido de ironía salvífica que se asoma en las páginas del escritor bogotano. Aborda el tema de la supuesta misoginia, a veces tan divulgada por los críticos, y demuestra la larga estela de amistades y de 
contertulios que valoraban su amplia cultura, su generosidad y su apertura. También el autor recalca que la riquísima biblioteca personal, de más de cuarenta mil volúmenes, requería horas de estudio y de reflexión que se proyectan en los densos textos gomezdavilianos. En este apartado se debaten temas como la identidad, la nacionalidad, lo latinoamericano y lo europeo, el papel del intelectual en la sociedad de hoy...

En el capítulo II "Obra, bibliografía e influencias", Serrano RuizCalderón ahonda aún más en las relaciones de Gómez Dávila con sus lecturas y los textos elaborados por él. Narra la historia de sus ediciones, así como la aparición sistematizada de los estudios sobre su vida y obra: monografías, libros colectivos, revistas monográficas, en diferentes idiomas. La presentación de las traducciones también es muy digna de la valoración. Sin duda, esta minuciosa relación presenta la importancia y la facilidad para estudiar y entender mejor el mundo de Gómez Dávila. Así mismo, las razones por las que despierta tanto interés entre los lectores de las diferentes culturas.

El capítulo III "El estilo del escoliasta" parece ser el más denso desde el punto de vista interpretativo de la obra del Solitario de Bogotá. Lo comprueban 101 pies de página, las numerosas digresiones, las asociaciones con otros autores; la abundancia de los fragmentos citados exige del lector un esfuerzo de concentración, pero también lo instruyen de forma particular. Miguel Serrano hilvana la idea de que la forma del escolio puede considerarse como la expresión muy apropiada para un reaccionario o un conservador. La nutrida lista de los autores allí comentados (resulta imposible enumerarlos en una reseña) permite establecer una riqueza conceptual en el campo de la tradición política y de sus rupturas de modo excepcional. Ciertamente, la exposición acerca de las batallas de reaccionarios, progresistas, modernistas y antimodernistas se ve enriquecida por la detallada y documentada exposición del autor. Vale la pena valorar igualmente las incursiones eruditas en el campo político con puntuales influencias literarias que permiten recrear un mundo cultural del siglo XIX y XX más comprensible.

El título del capítulo IV "Rechazo de la pedagogía y de la profesionalización de la cultura” refleja de una manera certera la posición de Gómez Dávila frente a los cambios que atraviesa la sociedad contem- 
poránea; por otro lado, el autor también delinea el conflicto que se puede percibir en las reflexiones de don Colacho acerca de la profesionalización de la filosofía, del utilitarismo de la educación, el pragmatismo del Estado y la deshumanización de las relaciones y condiciones de la persona humana. Gómez Dávila reclama y postula la contemplación como una postura en contra del tedio de la vida. En los subcapítulos dedicados a la inutilidad y lo útil y el supuesto progresismo, reclama la reconstrucción personal del pensamiento. La soledad es una condición antropológica de encontrarse consigo mismo para poder compartir con los demás.

El quinto capítulo “Textos implícitos en la obra de Nicolás Gómez Dávila” trata sobre los problemas clave de la sociedad actual. La democracia, como concepto, es un pretexto para analizar la historia de los últimos dos siglos y los cambios axiológicos de la sociedad. Serrano Ruiz-Calderón demuestra aquí la convicción de Gómez Dávila de que el hombre contemporáneo vive confundido por dar la espalda a la tradición occidental fundamentada en el cristianismo. Las ideas de las religiones políticas o de las relaciones antropoteistas, las manifestaciones gnósticas son procesos de desencantamiento del mundo. El voluntarismo, el progresismo, el determinismo universal implican la trasmutación de los valores, parecen secularizar la religión y cercenar cada vez más la libertad de la persona humana.

En consecuencia, no nos puede sorprender que Miguel Serrano cierre el libro con el capítulo VI "Dios y la nada, la superación del nihilismo”, temas de permanente búsqueda del filósofo bogotano. Parece ser que don Colacho, siendo siempre un hombre de fe consideraba ciertas teologías como reductoras de Dios, quien para él era fuente del conocimiento y de la vida. Entonces, cómo no recordar esta cita originaria de los Nuevos Escolios, y que aparece en la página 247 del libro: «Creer en Dios no es creer en Dios, es no poder no creer en él».

J. Miguel Serrano Ruiz-Calderón también, como su autor comentado, es un verdadero escoliasta. En el libro logró proyectar las interpretaciones de los autores que se anticiparon con sus publicaciones referentes a la obra de Nicolás Gómez Dávila que merecieron sus referencias, acotaciones, anotaciones, paráfrasis, citas, notas, apostillas o 
glosas. No hay ninguna exageración en afirmar que su estilo es escoliasta multiplicado o redimensionado, logrando de esta manera un juego literario que puede apreciarse como muy adecuado y aplaudido y, por otros, cuestionado. Sin embargo, al repetirse las mismas circunstancias -entre la fascinación y el rechazo, como la analizada creación de don Colacho- se puede reafirmar el aprecio por la ingeniosa intencionalidad en el proceso de su escritura. 